Review Article

\title{
Cardiac Autonomic Neuropathy: Why Should Cardiologists Care about That?
}

\author{
Andrzej Bissinger \\ Department of Interventional Cardiology and Arrhythmias, Medical University of Lodz, Lodz, Poland \\ Correspondence should be addressed to Andrzej Bissinger; abissinger@gmail.com
}

Received 11 March 2017; Revised 6 May 2017; Accepted 21 May 2017; Published 29 October 2017

Academic Editor: Norman Cameron

Copyright (C) 2017 Andrzej Bissinger. This is an open access article distributed under the Creative Commons Attribution License, which permits unrestricted use, distribution, and reproduction in any medium, provided the original work is properly cited.

\begin{abstract}
Background. Cardiac autonomic neuropathy (CAN) is a frequent but underdiagnosed complication of diabetes mellitus. It has a strong influence on various cardiac disorders including myocardial ischemia and infarction, hypertension, orthostatic hypotonia, heart failure, and arrhythmias. CAN can lead to severe morbidity and mortality and increase the risk of sudden cardiac death. Methods. This review article summarizes the latest evidence regarding the epidemiology, pathogenesis, influence on the cardiovascular system, and diagnostic methods for CAN. The methodology of this review involved analyzing available data from recent papers relevant to the topic of diabetic autonomic neuropathy and cardiac disorders. Conclusions. The early diagnosis of CAN can improve the prognosis and reduce adverse cardiac events. Methods based on heart rate variability enable the diagnosis of CAN even at a preclinical stage. These methods are simple and widely available for use in everyday clinical practice. According to the recently published Toronto Consensus Panel on Diabetic Neuropathy, all diabetic patients should be screened for CAN. Because diabetes mellitus often coexists with heart diseases and the most common methods used for diagnosis of CAN are based on ECG, not only diabetologists but also cardiologists should be responsible for diagnosis of CAN.
\end{abstract}

\section{Introduction}

Diabetes mellitus (DM) affects at least $8.5 \%$ of the global population, that is, about 422 million people worldwide [1]. Diabetes leads to complications in many parts of the body and can increase the overall risk of dying prematurely. Possible complications include heart attack, stroke, kidney failure, leg amputation, vision loss, and nerve damage. It is difficult to estimate the actual prevalence of diabetic complications, because especially microvascular complications are often underdiagnosed. The incidence of cardiac or cerebrovascular disease is two to four times higher in diabetic patients than in the general population. The leading cause of mortality and morbidity in patients with DM is cardiovascular diseases (CVD), such as coronary artery disease (CAD). The influence of diabetes on CAD is synergistic with other factors, such as age, hypercholesterolemia, hypertension, and smoking. Therefore, most preventive strategies focus on improving glycemic control, lowering blood pressure, and treating dyslipidemia [2]. Despite that CVD remains the major cause of mortality and morbidity in patients with DM, the autonomic nervous system (ANS) has an important influence on CVD. Two parts of the ANS-parasympathetic (PNS) and sympathetic (SNS) - cooperate to control heart rate, cardiac output, myocardial contractility, and constriction and dilatation of blood vessels [3]. Cardiac autonomic neuropathy has a major impact on CVD in diabetes. CAN is a very common complication of DM and very often not diagnosed. Based on the Subcommittee of the Toronto Consensus Panel on Diabetic Neuropathy, CAN is defined as the impairment of cardiovascular autonomic control in patients with established DM following the exclusion of other causes [4].

\section{Epidemiology and Pathogenesis}

There is huge variation in CAN prevalence depending on the diagnostic methods used, population studied, and disease stage. As reported in major studies, the number 
TABLe 1: Prevalence of cardiac autonomic neuropathy in different studies.

\begin{tabular}{|c|c|c|c|c|c|c|c|}
\hline Reference & Year & $\begin{array}{c}N \text { of } \\
\text { subjects }\end{array}$ & Type of DM & Population & $\begin{array}{l}\text { Diagnosis tests } \\
\text { for CAN }\end{array}$ & $\begin{array}{l}\text { Criteria } \\
\text { applied }\end{array}$ & $\begin{array}{c}\text { CAN } \\
\text { prevalence (\%) }\end{array}$ \\
\hline O'Brien [44] & 1991 & 506 & Type 1 & $\begin{array}{c}\text { Mean age } 45 \text { years, } \\
\text { mean DM duration } \\
15 \text { years }\end{array}$ & $\begin{array}{l}\text { HRV: rest, deep } \\
\text { breathing, Valsalva, } \\
\text { lying to standing }\end{array}$ & $\begin{array}{l}2 \text { or more } \\
\text { test positive }\end{array}$ & 17 \\
\hline \multirow{2}{*}{ Ziegler [59] } & \multirow{2}{*}{1992} & $\begin{array}{l}647 \\
524\end{array}$ & Type 1 & & $\begin{array}{l}\text { HRV: coefficient } \\
\text { of variations, }\end{array}$ & \multirow{2}{*}{$\begin{array}{l}3 \text { or more } \\
\text { test positive }\end{array}$} & 25.3 \\
\hline & & 524 & Type 2 & & $\begin{array}{l}\text { Valsalva, lying } \\
\text { to standing }\end{array}$ & & 34.3 \\
\hline Kennedy [60] & 1995 & 290 & Type 1 & $\begin{array}{c}\text { Potential recipients } \\
\text { of a pancreas } \\
\text { transplant }\end{array}$ & $\begin{array}{c}\text { Deep breathing } \\
\text { Valsalva }\end{array}$ & $\begin{array}{l}\text { Single test } \\
\text { positive }\end{array}$ & $\begin{array}{l}90 \\
88\end{array}$ \\
\hline Kempler [12] & 2002 & 3007 & Type 1 & $\begin{array}{c}\text { Mean age } 32 \text { years, } \\
\text { mean DM duration } \\
14 \text { years }\end{array}$ & $\begin{array}{l}\text { HR lying to standing, } \\
\text { postural BP }\end{array}$ & $\begin{array}{l}\text { Single test } \\
\text { positive }\end{array}$ & 36 \\
\hline Gaede [2] & 2003 & 160 & Type 2 & $\begin{array}{c}\text { Mean age } 55 \text { years, } \\
\text { HbA1c } 8.8 \% \text { at } \\
\text { baseline }\end{array}$ & $\begin{array}{l}\text { Deep breathing, } \\
\text { postural BP }\end{array}$ & $\begin{array}{l}\text { Single test } \\
\text { positive }\end{array}$ & 27.5 \\
\hline \multirow[t]{2}{*}{ Low [61] } & \multirow[t]{2}{*}{2004} & 83 & & & \multirow{2}{*}{$\begin{array}{c}\text { Sudomotor axon-reflex } \\
\text { test, Valsalva, BP and } \\
\text { HR response to } \\
\text { standing, deep } \\
\text { breathing }\end{array}$} & \multirow{2}{*}{$\begin{array}{l}2 \text { or more } \\
\text { test positive }\end{array}$} & 54 \\
\hline & & 148 & Type 2 & & & & 73 \\
\hline \multirow{2}{*}{ Pop-Busui [5] } & \multirow{2}{*}{2010} & 620 & $\begin{array}{l}\text { Type } 1 \text {-intensive } \\
\text { treatment group }\end{array}$ & \multirow{2}{*}{$\begin{array}{c}\text { Mean age } 47 \text { years, } \\
\text { mean DM } \\
\text { duration } \\
26 \text { years }\end{array}$} & \multirow{2}{*}{$\begin{array}{l}\text { Deep breathing, } \\
\text { Valsalva, } \\
\text { postural BP }\end{array}$} & \multirow{2}{*}{$\begin{array}{l}2 \text { or more } \\
\text { test positive }\end{array}$} & 29 \\
\hline & & 591 & $\begin{array}{l}\text { Type } 1-\text { conventional } \\
\text { treatment group }\end{array}$ & & & & 35 \\
\hline
\end{tabular}

DM: diabetes mellitus; CAN: cardiac autonomic neuropathy; HRV: heart rate variability; BP: blood pressure; HR: heart rate.

of patients with CAN varies from $17 \%$ to $90 \%$ in patients with DM type 1 and $27.5 \%$ to $73 \%$ in patients with DM type 2 (Table 1). The duration of diabetes is an independent factor for developing CAN irrespective of diabetes type $[4,5]$. CAN is detected in about $7 \%$ of patients with DM type 1 or 2 at the time of diagnosis, and it is estimated that the risk increases annually by about $6 \%$ and $2 \%$ in patients with DM type 1 and 2, respectively $[5,6]$. Other risk factors for developing CAN are poor glycemic control, age, obesity, smoking, hypertension, distal polyneuropathy, nephropathy, and retinopathy [3, 7]. Poor glycemic control is a major risk for CAN progression [7-9]. In the Diabetes Control and Complication Trial (DCCT), intensive glycemic control resulted in 50\% reduction in CAN incidence over the 6.5 years of follow-up [10]. Other interventions targeting hypertension, smoking, obesity, and hyperlipidemia also decrease the incidence of CAN $[2,11]$. The impact of gender on CAN is controversial. The EURODIAB IDDM Complications Study did not reveal differences in CAN frequency between men (35\%) and women (37\%) [12]. However, the ACCORD study showed that CAN was more prevalent in women $(2.6 \%$ of men versus $4.7 \%$ of women, $p<0.01$ ) [13].

CAN is caused by complex interactions and involves several mechanisms and pathways that lead to neuronal ischemia and finally neuronal death $[8,9]$. The leading cause of the pathogenic process is hyperglycemia $[3,5]$. Hyperglycemiainduced oxidative stress and toxic advanced glycosylation products lead to changes in mitochondrial functions, membrane permeability, and endothelial functions. These different pathways induce changes in gene expression, transcription factors, disruption of several cellular functions, and communication between the cells and surrounding matrix. All of this leads to neuronal dysfunction and death $[9,14]$.

The early stages of CAN damage the vagus nerve, thus leading to sympathetic predominance. This increase in sympathetic tone continues until advanced CAN, when sympathetic denervation also ensues [9].

Recent papers have also reported an association between hypoglycemia and the autonomic nervous system. Cichosz et al. found that the HRV parameter low frequency (LF) was significantly reduced during hypoglycemic episodes in patients with and without CAN [15]. Jaiswal et al. found that hypoglycemic stress reduced HRV power independently of glucose control as assessed by HbAlc [16]. These data suggest that not only hyperglycemia but also high glucose variability may contribute to CAN.

\section{Clinical Roles of CAN in Cardiology}

3.1. Coronary Artery Disease. Coronary artery disease (CAD) is a major complication of DM. The most typical clinical 
evidence of CAN in patients with concomitant CAD is silent myocardial ischemia (SMI) [17]. A meta-analysis of 12 studies showed that CAN is associated with SMI detected by the exercise test with prevalence ratios of 0.85 to 15.53 (the Mantel-Haenszel estimate for prevalence rate risk was 1.96, 95\% CI: 1.53-2.51, $p<0.001$ ) [6]. Several publications have reported the poor clinical outcome of patients with SMI. A threefold increase in cardiac deaths was witnessed over a 2-year follow-up in individuals with SMI detected during Holter ECG [18]. The Framingham Heart Study showed significantly higher incidence of painless myocardial infarction in patients with DM than without DM (39\% versus 22\%) [19]. A study of 120 patients with DM and no previous CAD found that CAN was a better predictor of major cardiovascular events (such as sudden death, death caused by MI, congestive heart failure, nonfatal MI, heart failure, resuscitation from ventricular tachycardia/fibrillation, and need for coronary revascularization) than the presence of SMI $(\mathrm{OR}=4.16,95 \% \mathrm{CI}: 1.01-17.19)$ and when CAN was combined with SMI the risk was even higher (5 out of 10 had a major event). CAN was also found to be associated with higher mortality risk in patients after myocardial infarction [20]. Features of myocardial infarction in patients with CAN may include dyspnea, fatigue, heart palpitations, hypotonia, nausea, and vomiting [21]. Although CAN might be used to stratify coronary artery risk and the screening of coronary artery disease might be beneficial in patients with CAN, there is no consensus on this point. The point of cost-effectiveness of this strategy has not been proven yet. After myocardial infarction, screening for CAN can be used for further risk stratification.

Autonomic dysfunction, assessed as reduced heart rate variability, was also associated with coronary artery calcification [22, 23]. Whether autonomic dysfunction is involved in the pathogenesis of atherosclerosis itself, it would have important implications for our understanding of the pathogenesis of coronary atherosclerosis in diabetic patients. A direct effect of autonomic dysfunction on atherosclerosis is certainly plausible. Sympathetic denervation may cause dedifferentiation of vascular smooth muscle cells and alteration to a phenotype associated with extracellular matrix production and migration to the intima, changes that have been observed in atherosclerosis [24,25]. An important issue is whether prevention of CAN might confer the added benefit of reduced coronary artery disease in diabetic patients.

3.2. Hypertension. Hypertension (HT) is well-known to place patients at risk for heart disease and often coexists with diabetes mellitus. Persistent HT increases the morbidity and mortality risk. Both the parasympathetic and sympathetic nervous systems innervate the heart and control heart rate (HR) (chronotropic activity) and strength of compression (inotropic activity). Only the SNS innervates the vasculature, thereby controlling peripheral resistance, and mediates the baroreceptor reflex (BRR), which in turn mediates blood pressure (BP). The angiotensin-renin system controls fluid levels in the body, including blood volume. Angiotensin directly affects the SNS, and the SNS indirectly affects angiotensin [26]. Conditions that result in increases in sympathetic activity may lead to chronic increases in BP and ultimately HT. A BP regulation abnormality related to CAN is due to the deterioration of its circadian rhythm. Decreases in parasympathetic tone at night lead to sympathetic prevalence and result in a lack of or less than $10 \%$ reduction in nocturnal blood pressure. Some patients with significant sympathetic predominance have a rise in blood pressure during the night in comparison with daytime blood pressure-this phenomenon is called "reverse dipping." Such "nondipper" or "reverse-dipper" CAN subjects more often experience left ventricular hypertrophy and cardiovascular events [27].

A frequent clinical manifestation of CAN is orthostatic hypotension. This phenomenon is defined as a decrease in systolic blood pressure $>20 \mathrm{mmHg}$ (or $>30 \mathrm{mmHg}$ in hypertensive patients) or diastolic blood pressure $>10 \mathrm{mmHg}$ when changing body position from supine to standing [21]. A change from lying to standing normally results in activation of a baroreceptor-initiated, centrally-mediated sympathetic reflex, resulting in an increase in peripheral vascular resistance and cardiac acceleration. In patients with diabetes, orthostatic hypotension is usually attributable to damage to the efferent sympathetic vasomotor fibers, particularly in the splanchnic vasculature [21]. Orthostatic hypotension causes many symptoms such as lightheadedness, dizziness, faintness, presyncope, and syncope. Orthostatic hypertension may make hypertension treatment difficult.

Also, there are clinical data indicating that CAN is associated with arterial stiffness [28-30]. Arterial stiffness leads to an increase in systolic blood pressure because the heart ejecting into a stiffening arterial bed must generate higher end-systolic pressures for the same net stroke volume. This leads to increased decay of arterial pressure and volume during systole, causing a reduced arterial volume at the onset of diastole, which in turn causes a fall in diastolic blood pressure. The direct clinical consequences of increased arterial stiffness are increased risk of stroke as a result of increased systolic blood pressure, left ventricular hypertrophy as a result of increased cardiac afterload, and decreased coronary perfusion owing to the decrease in diastolic blood pressure [31].

3.3. Heart Failure. CAN can lead to abnormalities in the left ventricular systolic and predominantly diastolic function. Echocardiographic studies showed that CAN is significantly associated with reduction in the peak diastolic filling and an increase in the atrial component of diastole [32]. Also, MRI showed that CAN is associated with increased LV mass and concentric remodeling as assessed by MRI independent of age, sex, and other factors [33]. However, abnormalities other than CAN in patients with DM, such as interstitial myocardial fibrosis and microangiopathic or metabolic changes, may also be responsible for left ventricular dysfunction. On the other hand, the parasympathetic denervation observed in the early stages of CAN leads to dominant sympathetic tone promoting metabolic changes, including high myocardial catecholamine levels [9]. This catecholamine rise has been reported to induce mitochondrial uncoupling, switching energy generation at cardiac level from 
glucose to free fatty acids and therefore increasing oxygen demand, and finally leading to hypertrophy and left ventricular remodeling. Alterations at the biochemical and cellular level lead to programmed cell death and fibrosis [34]. The result of these changes can be clinically present as heart failure, mainly with preserved left ventricular systolic function (diastolic heart failure), which is also related to high morbidity and mortality rates.

3.4. Arrhythmias. The ANS has an important influence on heart rhythm. The sinus node is innervated by the PNS and SNS, and the balance between these systems is important for control of HR.

Inappropriate sinus tachycardia is a common manifestation of CAN that occurs at a relatively early stage of the disease. An HR > $90 \mathrm{bpm}$ can be observed as a result of parasympathetic withdrawal. A fixed HR without changes during sleep, exercise, or stress is a sign of complete cardiac denervation. An impaired HR response to exercise leads to exercise intolerance [32].

The arrhythmia typically associated with changes of the ANS is atrial fibrillation (AF). In the 1990s, Phillipe Coumel stated that $\mathrm{AF}$ is not a homogeneous entity, and many factors are responsible for a number of different behaviors. He observed that the electrophysiological characteristics of atrial cells (action potential duration and refractoriness and conduction speed) are modulated differently by parasympathetic and sympathetic influences. Parasympathetic effects tend to favor macroreentry phenomena, whereas sympathetic ones favor abnormal automaticity and triggered activity [35]. In normal hearts, vagal influences are predominant, thus explaining why the clinical pattern of vagal-mediated paroxysmal AF is preferentially observed in the absence of detectable heart disease, in young male adults, with an ECG pattern of common flutter alternating with fibrillation. Sympathetically mediated AF is observed in the presence of any heart disease, the first effect of which is to provoke a vagal withdrawal. This clinical situation can be observed as a result of CAN, even in relatively early stages. In the group of DM patients with $\mathrm{CAN}$, a higher number of recurrences of paroxysmal AF are observed in comparison to DM without CAN (47 episodes per year versus 22 episodes per year, resp., $p<0.01$ ). This study also revealed that the presence of CAN caused a significant increase in P-wave duration and dispersion. That inhomogeneous atrial depolarization is the potential trigger of paroxysmal AF in patients with CAN [36].

The influence of CAN on nonsustained ventricular arrhythmias, according to our knowledge, is not welldocumented. However, life-threatening ventricular arrhythmias and sudden cardiac deaths are clearly associated with CAN $[5,7,8]$.

3.5. Mortality and Sudden Cardiac Death. CAN is associated with an increased total and cardiovascular mortality. In a meta-analysis of 15 studies, Maser et al. [37] found that the pooled-estimated relative mortality risk was 2.14 (95\% CI: $1.83-2.51, p<0.0001)$ for CAN patients. The magnitude of the association was stronger for those studies for which two or more measures were used to define CAN. The pooled relative risk for studies that defined CAN with the presence of two or more abnormalities was 3.45 (95\% CI 2.66-4.47; $p<0.001)$ compared with $1.20(1.02-1.41 ; p=0.03)$ for studies that used one measure. CAN also had the strongest association with mortality among other risk factors in the EURODIAB IDMM Complications Study [38]. In the population of the ACCORD trial, which included patients with high risk of cardiovascular event, CAN was an independent risk factor of all-cause mortality (HR 2.14, 95\% CI: $1.37-$ 3.37 ) and cardiovascular mortality (HR 2.62, 95\% CI: $1.4-$ 4.91) after a mean follow-up of 3.5 years [13].

CAN is also associated with a higher risk of malignant ventricular arrhythmias and sudden death [39]. On the one hand, severe silent ischemia or myocardial infarction can induce life-threatening arrhythmia and sudden death. Additionally, lethal arrhythmias can be explained directly by an imbalance between the sympathetic and parasympathetic parts of the ANS. The EURODIAB IDDM Complication Study showed the association between CAN and QT prolongation [40]. Other studies also confirmed the influence of CAN on QT prolongation $[41,42]$. It has been postulated that QT prolongation predisposes to cardiac arrhythmias and sudden death.

Other mechanisms depending on autonomic imbalance, such as impaired response to hypoxic state, reduced hypoglycemia awareness, and prolonged hypoglycemia episodes, can also be responsible for malignant ventricular arrhythmias and finally lead to sudden death $[43,44]$.

\section{Diagnosis of CAN}

Traditionally, the diagnostic methods of cardiac autonomic neuropathy are based on heart rate variability (HRV) and changes in BP during certain physiological maneuvers. In the 1970s, Ewing et al. [45] proposed five simple tests to measure autonomic functions. These test are (1) the R-R alterations to paced deep breathing (expiration:inspiration ratio and E:I ratio); (2) HR response to standing-30:15 ratio-which is the ratio of the longest $R-R$ interval (between the 20th and 40th beat) to the shortest interval (between the 5th and 25th beat) elicited by a position change from horizontal to vertical; (3) the HR response during the Valsalva maneuver; (4) the BP response to standing; and (5) the BP response to sustained handgrip caused by the muscle contraction using a handgrip dynamometer (Table 2).

The first two tests measure parasympathetic functionmainly the ability of the vagal nerve to slow the HR during procedures which increase HR. The Valsalva maneuver primarily represents also parasympathetic activity, but autonomic changes also include a sympathetic component. The last two tests show changes in sympathetic function and involve baroreflex-mediated blood presser fluctuations. The American Diabetes Association recommends the use of these Ewing's tests in the diagnosis of CAN [46].

According to the Toronto Diabetic Neuropathy Expert Group, the most widely used tests assessing cardiac parasympathetic function are based on the time-domain HR response to deep breathing, a Valsalva maneuver, and postural change. Of these tests, HR to deep breathing has the 
TABle 2: Ewing's tests and CAN diagnosis.

\begin{tabular}{|c|c|}
\hline Test & Description \\
\hline $\begin{array}{l}\text { Expiration/inspiration } \\
(\mathrm{E} / \mathrm{I}) \text { ratio }\end{array}$ & $\begin{array}{l}\text { The patient was asked to take deep } \\
\text { breaths for } 10 \text { minutes with } \\
\text { frequency about } 6 \text { breaths } / \mathrm{min} \text {. }\end{array}$ \\
\hline Valsalva maneuver & $\begin{array}{l}\text { The patient was asked to blow } \\
\text { into the special manometer } \\
\text { to maintain the pressure at } \\
\text { about } 40 \mathrm{mmHg} \text { for } 15 \mathrm{~s} .\end{array}$ \\
\hline $\begin{array}{l}\text { Postural heart rate } \\
\text { response: maximum- } \\
\text { minimum ( } 30: 15 \text { ratio })\end{array}$ & $\begin{array}{l}\text { Heart rate was measured in } \\
\text { the horizontal position and } \\
\text { again two minutes later after } \\
\text { standing upright. }\end{array}$ \\
\hline $\begin{array}{l}\text { Postural blood } \\
\text { pressure response }\end{array}$ & $\begin{array}{c}\text { Blood pressure was measured } \\
\text { in the horizontal position and } \\
\text { after } 1,3 \text {, and } 5 \text { minutes after } \\
\text { standing upright. }\end{array}$ \\
\hline Isometric handgrip test & $\begin{array}{l}\text { The patient was asked to grip the } \\
\text { dynamometer for } 5 \text { minutes. }\end{array}$ \\
\hline
\end{tabular}

greatest specificity ( 80\%). Cardiovascular sympathetic function is assessed by measuring the BP response to orthostatic change and a Valsalva maneuver [47]. The experts did not recommend the handgrip test, but this test is still used in clinical studies [48].

The short-term ECG recordings can be analyzed by dedicated software in the frequency domain. This method usually uses the Fourier method, which transforms R-R intervals into waves with three basic components: very low frequency $\leq 0.04 \mathrm{~Hz}$ (VLF), low frequency $0.04-0.15 \mathrm{~Hz}$ (LF), and high frequency $0.15-0.4 \mathrm{~Hz}$ (HF). HF represents vagal activity, whereas LF combines the effect of sympathetic and parasympathetic influence. A decrease in HF is a sign of parasympathetic dysfunction, in the early stages of autonomic dysfunction in diabetes, when sympathetic predominance is observed it leads to an increase in LF/HF [49].

It is not clear if classical Ewing's tests or time-domain methods are better for diagnosis of CAN. Studies comparing the two methods showed high-over 80\%-correlations between their results [50]. However, Ewing's tests are simpler and can be more easily implemented during routine clinical use.

Another diagnostic method of CAN can be based on HRV assessed during classic $24 \mathrm{~h}$ Holter ECG monitoring and use of statistical indexes in the time and frequency domain. It is obvious that reduction in HRV is associated with CAN, but this method has no standard values for the diagnosis of CAN [51]. Also, during $24 \mathrm{~h}$ recording, many factors can have an influence on HRV parameters, such as concomitant illness, use of medication, and lifestyle factors (exercise, stress, smoking, etc.). The literature has been described in detail regarding HRV analysis based on Holter ECG, but it is beyond the scope of this article [49].

The baroreceptor reflex (BRR) is another method that can be used for detecting CAN. In the physiological BRR, an increase of BP induces an increase in the vagal cardiac efferent and reduction in the sympathetic activity, resulting in bradycardia, hypotension, and peripheral vasodilatation
[52]. A reduction in BP induces opposite responses. The BRR test can be used for detecting CAN and correlates very well with the classical Ewing's tests [53]. Studies on patients with DM have concluded that an impaired BRR is a strong independent risk factor for mortality [54].

Another Holter-based technique for evaluating CAN is heart rate turbulence (HRT). HRT is an indirect measurement of baroreflex sensitivity and refers to sinus rhythm fluctuations following premature ventricular beat. Physiologically, after ventricular beat, sinus rate acceleration and next deceleration are observed. There are two components of HRT-turbulence onset (TO) and turbulence slope (TS). The initial heart rhythm acceleration after ventricular premature beat is defined as TO and the ensuring deceleration as TS [55]. HRT parameters could be a useful monitoring tool for the function of the autonomic nervous system in patients with diabetes mellitus [56]. Balcioğlu et al. [57] revealed that decreased TS has a correlation with CAN severity. Although HRT tests are not standardized for detection of CAN and have no cutoff values for diagnosis of CAN, TS $<3.32 \mathrm{~ms} / \mathrm{R}-\mathrm{R}$ was $97 \%$ sensitive and $71 \%$ specific for diagnosis of CAN as detected by Ewing's tests [57]. The major limitation concerning the measurement of HRT is that the presence of ventricular premature beats is mandatory for its evaluation.

Other methods currently used in the detection of CAN are single photon emission computed tomography (SPECT) and positron emission tomography (PET) with sympathetic neurotransmitter analogs such as ${ }^{123}$ I-metaiodobenzylguanidine $\left({ }^{123} \mathrm{I}-\mathrm{MIBG}\right),{ }^{11} \mathrm{C}$-metahydroxyephedrine $\left({ }^{11} \mathrm{C}-\mathrm{HED}\right)$, and ${ }^{11} \mathrm{C}$-epinephrine [9].

The lack of standardization, the high cost, and the requirement of specific equipment and skilled staff restrict the role of scintigraphy as a research tool, and it is not a part of everyday clinical practice.

According to the latest Standards of Medical Care in Diabetes published by the American Diabetes Association, symptoms and signs of autonomic neuropathy should be assessed in patients with microvascular and neuropathic complications. CAN may be completely asymptomatic and detected only by decreased heart rate variability with deep breathing. Major clinical manifestations of CAN include resting tachycardia $(>100 \mathrm{bpm})$ and orthostatic hypotension (a fall in systolic or diastolic blood pressure by $>20 \mathrm{mmHg}$ or $>10 \mathrm{mmHg}$, resp., upon standing without an appropriate increase in heart rate) [58].

\section{Stages and Diagnostic Criteria for CAN}

Ewing's tests (Table 2) are the gold standard clinical tests for the diagnosis of CAN. The reference values for an abnormal test are age-dependent. According to the CAN Subcommittee of the Toronto Consensus Panel [52], only one abnormal test is sufficient to diagnose possible or early CAN. Two or more abnormal tests indicate definite CAN. The presence of orthostatic hypotension in addition to abnormal tests signifies severe CAN [52].

For bedside testing, a dedicated software can be used. The authors have personal experience with ProSciCard III (MEWICON CATEEM-Tec GmbH, Germany), which offers 


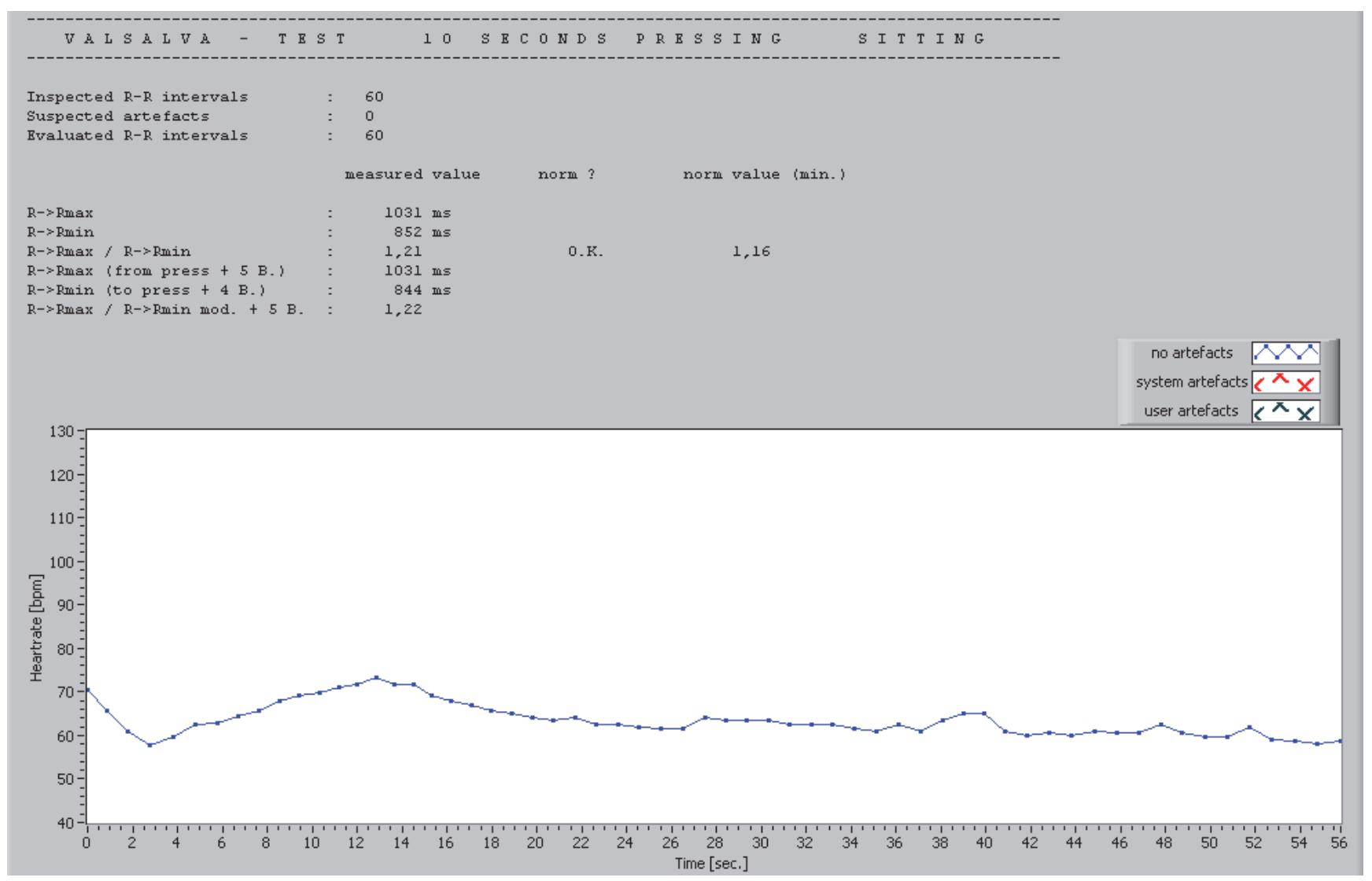

FIgURE 1: Example of normal Valsalva test.

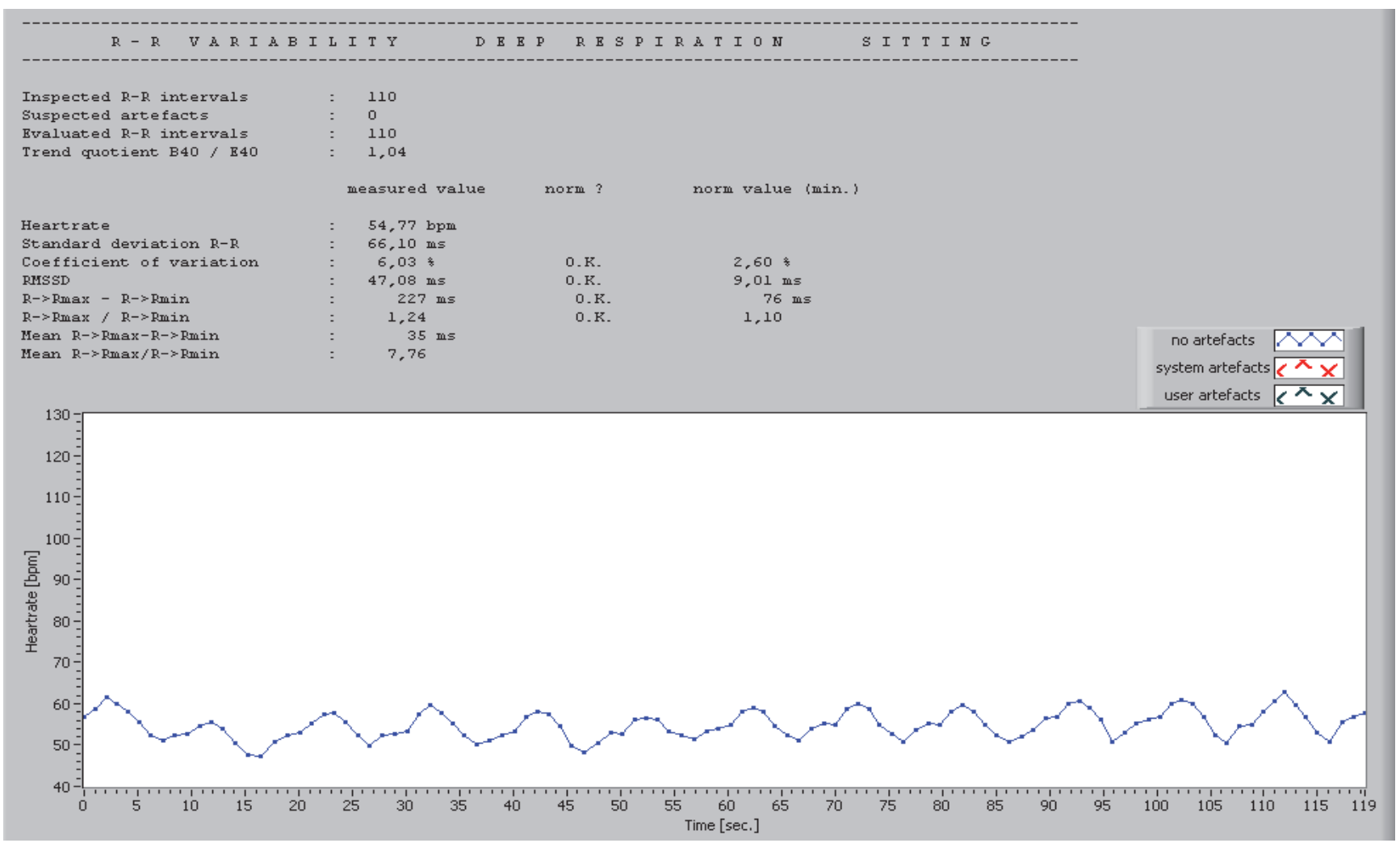

FIGURE 2: Example of normal deep respiration test. 
the possibility of an online ECG measurement and a subsequent offline detailed analysis with comparison to normal values. The tests included in the software are RR variability at rest (over 170 intervals, 5, 10, or $30 \mathrm{~min}$ ), RR variability during deep breathing, Valsalva test (10 or $15 \mathrm{~s}$ ), and orthostasis test. The results are not only typical Ewing's parameters but also time and frequency domain HRV during each test. Examples of normal tests are presented in Figures 1 and 2.

\section{Conclusions}

CAN is a frequent chronic complication of DM with potentially life-threatening outcomes. Although there are available simple bedside tests for diagnosis of CAN, it is often overlooked. The statements of the Toronto Diabetic Neuropathy Experts Group recommended screening for all diabetic patients [52]. Because CAN has a significant negative influence on coexisting heart diseases and the most common methods used for the diagnosis of CAN are based on ECG, cardiologists should also be responsible for diagnosis of CAN.

\section{Conflicts of Interest}

The author declares that he has no conflicts of interest.

\section{References}

[1] "Global report on diabetes. WHO Library Cataloguing-inPublication Data, World Health Organization 2016," http:// www.who.int/diabetes/publications/grd-2016/en/.

[2] P. Gaede, P. Vedel, N. Larsen, G. V. Jensen, H. H. Parving, and O. Pedersen, "Multifactorial intervention and cardiovascular disease in patients with type 2 diabetes," The New England Journal of Medicine, vol. 348, no. 5, pp. 383-393, 2003.

[3] A. I. Vinik and T. Erbas, "Chapter 22 - diabetic autonomic neuropathy," Handbook of Clinical Neurology, vol. 117, pp. 27-94, 2013.

[4] V. Spallone, D. Ziegler, R. Freeman et al., "Cardiovascular autonomic neuropathy in diabetes: clinical impact, assessment, diagnosis, and management," Diabetes/Metabolism Research and Reviews, vol. 27, no. 7, pp. 639-653, 2011.

[5] R. Pop-Busui, "Cardiac autonomic neuropathy in diabetes: a clinical perspective," Diabetes Care, vol. 33, no. 2, pp. 434441, 2010.

[6] A. I. Vinik, R. Freeman, and T. Erbas, "Diabetic autonomic neuropathy," Seminars in Neurology, vol. 23, no. 4, pp. 365372, 2003.

[7] D. Ziegler, "Diabetic cardiovascular autonomic neuropathy: prognosis, diagnosis and treatment," Diabetes/Metabolism Reviews, vol. 10, no. 4, pp. 339-383, 1994.

[8] A. S. Balcıoğlu and H. Müderrisoğlu, "Diabetes and cardiac autonomic neuropathy: clinical manifestations, cardiovascular consequences, diagnosis and treatment," World Journal of Diabetes, vol. 6, no. 1, pp. 80-91, 2015.

[9] G. Dimitropoulos, A. A. Tahrani, and M. J. Stevens, "Cardiac autonomic neuropathy in patients with diabetes mellitus," World Journal of Diabetes, vol. 5, no. 1, pp. 17-39, 2014.

[10] The DiabetesControl and Complications Trial Research Group, "The effect of intensive diabetes therapy on measures of autonomic nervous system function in the Diabetes Control and Complications Trial (DCCT)," Diabetologia, vol. 41, no. 4, pp. 416-423, 1998.

[11] R. E. Maser, M. A. Pfeifer, J. S. Dorman, L. H. Kuller, D. J. Becker, and T. J. Orchard, "Diabetic autonomic neuropathy and cardiovascular risk. Pittsburgh Epidemiology of Diabetes Complications Study III," Archives of Internal Medicine, vol. 150, no. 6, pp. 1218-1222, 1990.

[12] P. Kempler, S. Tesfaye, N. Chaturvedi et al., "Autonomic neuropathy is associated with increased cardiovascular risk factors: the EURODIAB IDDM Complications Study," Diabetic Medicine, vol. 19, no. 11, pp. 900-909, 2002.

[13] R. Pop-Busui, G. W. Evans, H. C. Gerstein et al., "Effects of cardiac autonomic dysfunction on mortality risk in the Action to Control Cardiovascular Risk in Diabetes (ACCORD) trial," Diabetes Care, vol. 33, no. 7, pp. 1578-1584, 2010.

[14] J. W. Albers and R. Pop-Busui, "Diabetic neuropathy: mechanisms, emerging treatments, and subtypes," Current Neurology and Neuroscience Reports, vol. 14, no. 8, p. 473, 2014.

[15] S. L. Cichosz, J. Frystyk, L. Tarnow, and J. Fleischer, "Are changes in heart rate variability during hypoglycemia confounded by the presence of cardiovascular autonomic neuropathy in patients with diabetes?," Diabetes Technology \& Therapeutics, vol. 19, no. 2, pp. 91-95, 2017.

[16] M. Jaiswal, K. McKeon, N. Comment et al., “Association between impaired cardiovascular autonomic function and hypoglycemia in patients with type 1 diabetes," Diabetes Care, vol. 37, no. 9, pp. 2616-2621, 2014.

[17] F. J. T. Wackers, L. H. Young, S. E. Inzucchi et al., "Detection of silent myocardial ischemia in asymptomatic diabetic subjects: the DIAD study," Diabetes Care, vol. 27, no. 8, pp. 1954-1961, 2004.

[18] P. C. Deedwania and E. V. Carbajal, "Silent ischemia during daily life is an independent predictor of mortality in stable angina," Circulation, vol. 81, no. 3, pp. 748-756, 1990.

[19] W. B. Kannel and R. D. Abbott, "Incidence and prognosis of unrecognized myocardial infarction - an update on the Framingham Study," The New England Journal of Medicine, vol. 311, no. 18, pp. 1144-1147, 1984.

[20] H. Miettinen, S. Lehto, V. Salomaa et al., "Impact of diabetes on mortality after the first myocardial infarction," Diabetes Care, vol. 21, no. 1, pp. 69-75, 1998.

[21] A. I. Vinik and D. Ziegler, "Diabetic cardiovascular autonomic neuropathy," Circulation, vol. 115, no. 3, pp. 387-397, 2007.

[22] S. M. Dayem, A. A. Battah, and M. Bohy Ael, "Cardiovascular autonomic neuropathy and early atherosclerosis in adolescent type 1 diabetic patient," Open Access Macedonian Journal of Medical Sciences, vol. 3, no. 4, pp. 681-688, 2015.

[23] H. M. Colhoun, D. P. Francis, M. B. Rubens, S. R. Underwood, and J. H. Fuller, "The association of heart-rate variability with cardiovascular risk factors and coronary artery calcification: a study in type 1 diabetic patients and the general population," Diabetes Care, vol. 24, no. 6, pp. 1108-1114, 2001.

[24] K. Kacem, G. Bonvento, and J. Seylaz, "Effect of sympathectomy on the phenotype of smooth muscle cells of middle cerebral and ear arteries of hyperlipidaemic rabbits," The Histochemical Journal, vol. 29, no. 4, pp. 279-286, 1997.

[25] V. Dimitriadou, P. Aubineau, J. Taxi, and J. Seylaz, "Ultrastructural changes in the cerebral artery wall induced by long-term sympathetic denervation," Blood Vessels, vol. 25, no. 3, pp. 122-143, 1988. 
[26] J. Colombo, R. Arora, N. L. DePace, and C. Ball, Clinical Autonomic Dysfunction, Springer International Publishing, Switzerland, 2014.

[27] V. Spallone, L. Bernardi, L. Ricordi et al., "Relationship between the circadian rhythms of blood pressure and sympathovagal balance in diabetic autonomic neuropathy," Diabetes, vol. 42, no. 12, pp. 1745-1752, 1993.

[28] C. T. Prince, A. M. Secrest, R. H. Mackey, V. C. Arena, L. A. Kingsley, and T. J. Orchard, "Cardiovascular autonomic neuropathy, HDL cholesterol, and smoking correlate with arterial stiffness markers determined 18 years later in type 1 diabetes," Diabetes Care, vol. 33, no. 3, pp. 652-657, 2010.

[29] C. Meyer, F. Milat, B. P. McGrath, J. Cameron, D. Kotsopoulos, and H. J. Teede, "Vascular dysfunction and autonomic neuropathy in type 2 diabetes," Diabetic Medicine, vol. 21, no. 7, pp. 746-751, 2004.

[30] A. R. Ahlgren, G. Sundkvist, P. Wollmer, B. Sonesson, and T. Länne, "Increased aortic stiffness in women with type 1 diabetes mellitus is associated with diabetes duration and autonomic nerve function," Diabetic Medicine, vol. 16, no. 4, pp. 291-297, 1999.

[31] C. D. Stehouwer, R. M. Henry, and I. Ferreira, "Arterial stiffness in diabetes and the metabolic syndrome: a pathway to cardiovascular disease," Diabetologia, vol. 51, no. 4, pp. 527-539, 2008.

[32] R. Pop-Busui, "What do we know and we do not know about cardiovascular autonomic neuropathy in diabetes," Journal of Cardiovascular Translational Research, vol. 5, no. 4, pp. 463478, 2012.

[33] R. Pop-Busui, P. A. Cleary, B. H. Braffett et al., "Association between cardiovascular autonomic neuropathy and left ventricular dysfunction: DCCT/EDIC study (Diabetes Control and Complications Trial/Epidemiology of Diabetes Interventions and Complications)," Journal of the American College of Cardiology, vol. 61, no. 4, pp. 447-454, 2013.

[34] A. Frustaci, J. Kajstura, C. Chimenti et al., "Myocardial cell death in human diabetes," Circulation Research, vol. 87, no. 12, pp. 1123-1132, 2000.

[35] P. Coumel, "Autonomic influences in atrial tachyarrhythmias," Journal of Cardiovascular Electrophysiology, vol. 7, no. 10, pp. 999-1007, 1996.

[36] A. Bissinger, T. Grycewicz, W. Grabowicz, and A. Lubinski, "The effect of diabetic autonomic neuropathy on P-wave duration, dispersion and atrial fibrillation," Archives of Medical Science, vol. 7, no. 5, pp. 806-812, 2011.

[37] R. E. Maser, B. D. Mitchell, A. I. Vinik, and R. Freeman, "The association between cardiovascular autonomic neuropathy and mortality in individuals with diabetes: a meta-analysis," Diabetes Care, vol. 26, no. 6, pp. 1895-1901, 2003.

[38] S. S. Soedamah-Muthu, N. Chaturvedi, D. R. Witte et al., "Relationship between risk factors and mortality in type 1 diabetic patients in Europe: the EURODIAB Prospective Complications Study (PCS)," Diabetes Care, vol. 31, no. 7, pp. 1360-1366, 2008.

[39] C. W. Israel and Y. H. Lee-Barkey, "Sudden cardiac death in diabetes mellitus," Herz, vol. 41, no. 3, pp. 193-200, 2016.

[40] M. Veglio, M. Borra, L. K. Stevens, J. H. Fuller, and P. C. Perin, "The relation between QTc interval prolongation and diabetic complications. The EURODIAB IDDM Complication Study Group," Diabetologia, vol. 42, no. 1, pp. 68-75, 1999.
[41] J. M. Pappachan, J. Sebastian, B. C. Bino et al., "Cardiac autonomic neuropathy in diabetes mellitus: prevalence, risk factors and utility of corrected QT interval in the ECG for its diagnosis," Postgraduate Medical Journal, vol. 84, no. 990, pp. 205-210, 2008.

[42] A. Bissinger, L. Markuszewski, and M. Rosiak, "Value and circadian variations of QT dispersion in patients with diabetes mellitus and coronary artery disease," Polski Merkuriusz Lekarski, vol. 24, no. 140, pp. 90-94, 2008.

[43] M. M. Page and P. J. Watkins, "Cardiorespiratory arrest and diabetic autonomic neuropathy," Lancet, vol. 1, no. 8054, pp. 14-16, 1978.

[44] I. A. O'Brien, J. P. McFadden, and R. J. M. Corrall, "The influence of autonomic neuropathy on mortality in insulindependent diabetes," QJM: An International Journal of Medicine, vol. 79, no. 3, pp. 495-502, 1991.

[45] D. J. Ewing, I. W. Campbell, and B. F. Clarke, "Assessment of cardiovascular effects in diabetic autonomic neuropathy and prognostic implications," Annals of Internal Medicine, vol. 92, no. 2, Part 2, pp. 308-311, 1980.

[46] A. J. M. Boulton, A. I. Vinik, J. C. Arezzo et al., "Diabetic neuropathies: a statement by the American Diabetes Association," Diabetes Care, vol. 28, no. 4, pp. 956-962, 2005.

[47] S. Tesfaye, A. J. Boulton, P. J. Dyck et al., "Diabetic neuropathies: update on definitions, diagnostic criteria, estimation of severity, and treatments," Diabetes Care, vol. 33, no. 10, pp. 2285-2293, 2010.

[48] A. S. Menon, A. Dixit, M. K. Garg, and R. Girish, "Cardiac autonomic neuropathy in patients with type 2 diabetes mellitus at high risk for foot ulcers," Indian Journal of Endocrinology and Metabolism, vol. 21, no. 2, pp. 282-285, 2017.

[49] Task Force of the European Society of Cardiology and the North American Society of Pacing and Electrophysiology, "Heart rate variability: standards of measurement, physiological interpretation and clinical use," Circulation, vol. 93, no. 5, pp. 1043-1065, 1996.

[50] K. Howorka, J. Pumprla, A. Schabmann, and H. Thoma, "Development of an analytic standard for evaluating heart rate variability in cardiovascular autonomic neuropathy in diabetes: comparison of short-term spectral analysis with Ewing's standard battery of reflex tests as reference method," Biomedizinische Technik/Biomedical Engineering, vol. 43, pp. 568-569, 1998.

[51] S. Sammito and I. Böckelmann, "Reference values for timeand frequency-domain heart rate variability measures," Heart Rhythm, vol. 13, no. 6, pp. 1309-1316, 2016.

[52] L. Bernardi, V. Spallone, M. Stevens et al., "Methods of investigation for cardiac autonomic dysfunction in human research studies," Diabetes/Metabolism Research and Reviews, vol. 27, no. 7, pp. 654-664, 2011.

[53] E. Borowik, W. Grabowicz, T. Grycewicz, and A. Lubiński, "Clinical usefulness of baroreflex sensitivity test in the detection of cardiovascular autonomic neuropathy in patients with type 2 diabetes mellitus," Polski Merkuriusz Lekarski, vol. 39, no. 233, pp. 277-280, 2015.

[54] J. Gerritsen, J. M. Dekker, B. J. TenVoorde et al., "Impaired autonomic function is associated with increased mortality, especially in subjects with diabetes, hypertension, or a history of cardiovascular disease: the Hoorn Study," Diabetes Care, vol. 24 , no. 10, pp. 1793-1798, 2001. 
[55] A. Bauer, M. Malik, G. Schmidt et al., "Heart rate turbulence: standards of measurement, physiological interpretation, and clinical use: International Society for Holter and Noninvasive Electrophysiology Consensus," Journal of the American College of Cardiology, vol. 52, no. 17, pp. 1353-1365, 2008.

[56] A. Bissinger, J. Ruxer, R. B. Ahmed, and A. Lubinski, "Heart rate turbulence in patients with poorly controlled diabetes mellitus type 2," Archives of Medical Science, vol. 10, no. 6, pp. 1073-1077, 2014.

[57] S. Balcioğlu, U. Arslan, S. Türkoğlu, M. Ozdemir, and A. Cengel, "Heart rate variability and heart rate turbulence in patients with type 2 diabetes mellitus with versus without cardiac autonomic neuropathy," The American Journal of Cardiology, vol. 100, no. 5, pp. 890-893, 2007.

[58] American Diabetes Association, "10. Microvascular complications and foot care," Diabetes Care, vol. 40, Supplement 1, pp. S88-S98, 2017.

[59] D. Ziegler, F. A. Gries, M. Spüler, and F. Lessmann, “The epidemiology of diabetic neuropathy. Diabetic Cardiovascular Autonomic Neuropathy Multicenter Study Group," Journal of Diabetes and its Complications, vol. 6, no. 1, pp. 49-57, 1992.

[60] W. R. Kennedy, X. Navarro, and D. E. Sutherland, "Neuropathy profile of diabetic patients in a pancreas transplantation program," Neurology, vol. 45, no. 4, pp. 773-780, 1995.

[61] P. A. Low, L. M. Benrud-Larson, D. M. Sletten et al., "Autonomic symptoms and diabetic neuropathy: a populationbased study," Diabetes Care, vol. 27, no. 12, pp. 2942-2947, 2004. 


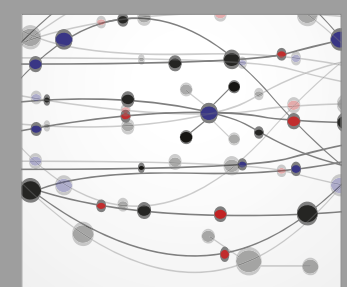

The Scientific World Journal
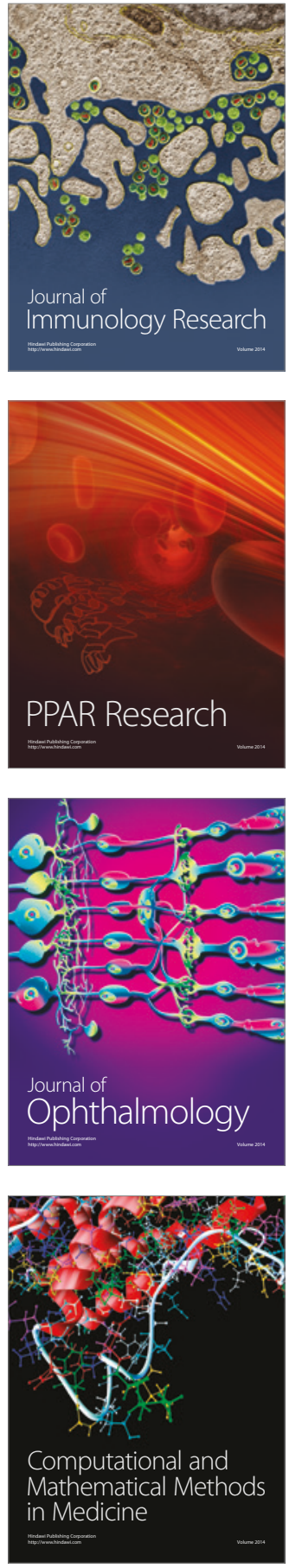

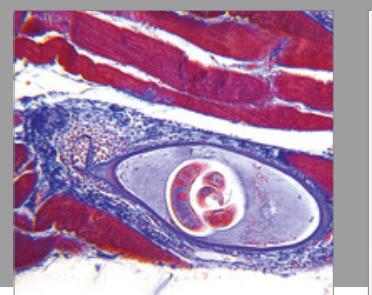

Gastroenterology Research and Practice
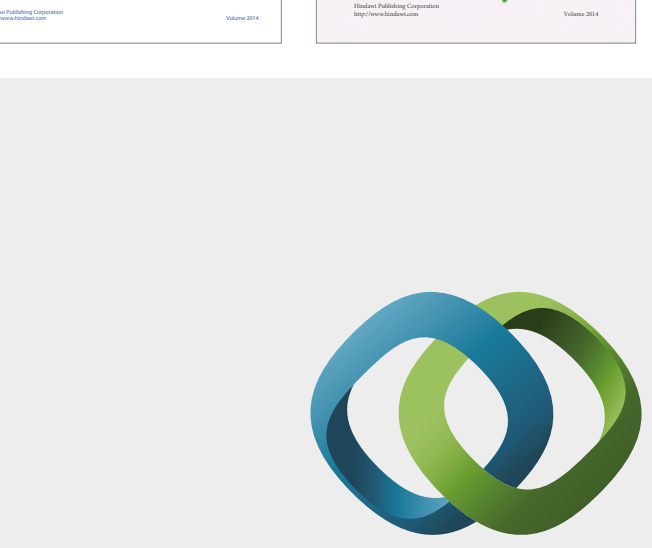

\section{Hindawi}

Submit your manuscripts at

https://www.hindawi.com
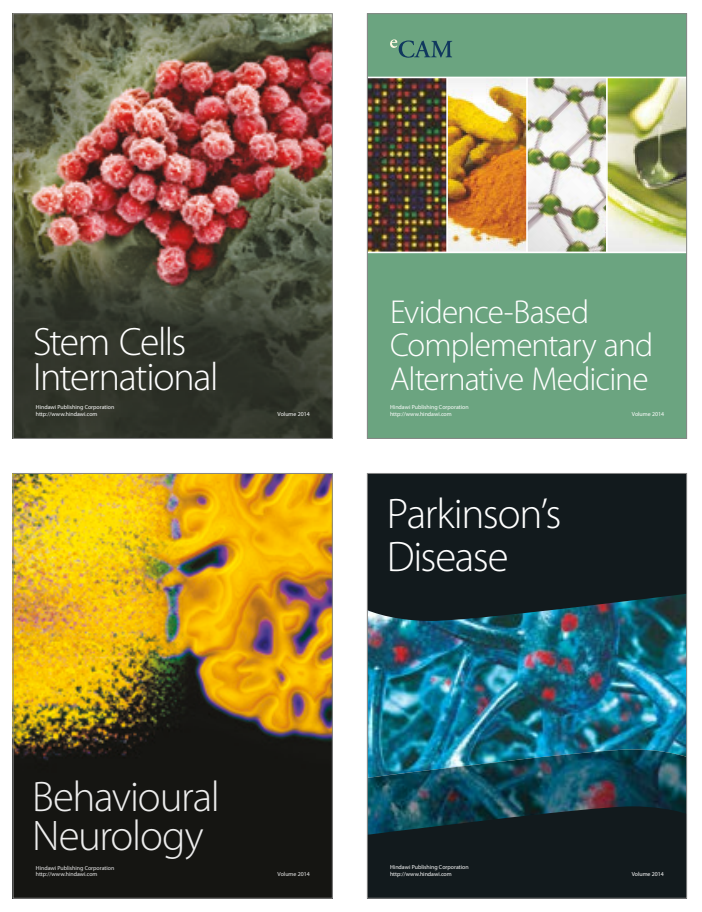
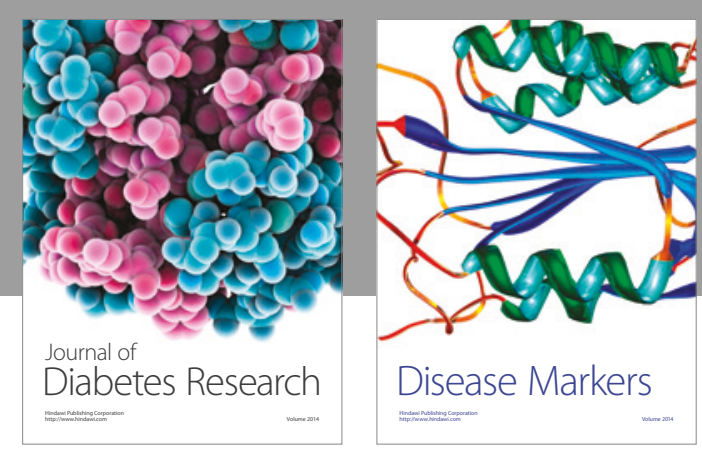

Disease Markers
